\title{
INFLUÊNCIAS DA REGULAÇÃO NA QUALIDADE DAS INFORMAÇÕES CONTÁBEIS NO ÂMBITO DO MERCADO DE CAPITAIS: UM ENSAIO TEÓRICO
}

\author{
INFLUENCE OF REGULATION ON EARNINGS QUALITY IN THE CAPITAL MARKETS \\ ENVIROMENT: A THEORETICAL ESSAY
}

\section{INFLUENCIAS DE LA REGULACIÓN SOBRE LA CALIDAD DE LA INFORMACIÓN CONTABLE EN EL ENTORNO DE LOS MERCADOS DE CAPITALES: UNA PRUEBA TEÓRICA}

Recebido em: 04-01-2017

Avaliado em: 03-08-2020

Reformulado em: 13-09-2020

Aceito para publicação em: 16-03-2021

Publicado em: 26-04-2021

Editor Responsável: Moacir Manoel Rodrigues Jr.
Géssica Cappellesso ${ }^{1}$

Jorge Katsumi Niyama ${ }^{2}$

Jomar Miranda Rodrigues ${ }^{3}$

\section{RESUMO}

O estudo teve como objetivo discutir, de forma teórica, como a regulação da contabilidade pode influenciar a qualidade das informações contábeis divulgadas ao mercado de capitais. Para isso, considerou-se a regulação como uma determinante direta da qualidade da informação contábil, além da sua capacidade de influenciar as características de gerenciamento de resultados, conservadorismo e reconhecimento oportuno das perdas, consideradas proxies da qualidade da informação contábil. A discussão aponta que a regulação da contabilidade afeta a qualidade da informação mediante seus papeis de monitoramento, normatização e enforcement, sendo esses complementares. Como monitor, os órgãos reguladores do mercado de capitais buscariam melhorar a qualidade das informações contábeis, restringindo o gerenciamento de resultados e favorecendo o conservadorismo e o reconhecimento oportuno das perdas. A normatização, como a adoção das IFRS e SOX, também tem esses objetivos, mas a regulação pode acabar fornecendo incentivos para o gerenciamento de resultados, devido ao escrutínio regulatório e às consequências políticas adversas. Enfim, o nível de enforcement, representado pelo ambiente institucional, busca garantir a aplicação das normas e o atendimento do objetivo da regulação, sendo um moderador importante para determinar como a regulação influenciaria efetivamente a qualidade da informação contábil. Portanto, conclui-se que a regulação da contabilidade é capaz de influenciar a qualidade da informação contábil de forma direta e indireta, mas que nem sempre os efeitos serão uniformes em todos os países, pois irá depender do nível de enforcement.

Palavras-chave: Qualidade das informações contábeis. Regulação da contabilidade. Conservadorismo. Reconhecimento oportuno das perdas. Gerenciamento de resultados.

\footnotetext{
${ }^{1}$ Doutoranda em Ciências Contábeis Universidade de Brasília; E-mail: gessica_cappellesso@hotmail.com

2 Doutor em Controladoria e Contabilidade - FEA/USP; Pós- doutorado pela Universidade de Otago; Professor da Universidade de Brasília; E-mail: jkatsumi@unb.br

${ }^{3}$ Doutor em Ciências Contábeis - Programa Multi-Institucional, Inter-Regional de Pós-Graduação em Ciências Contábeis da UnB/UFPB/UFRN; Professor da Universidade de Brasília; E-mail: jomar@unb.br
} 


\section{ABSTRACT}

Theoretically, the study aimed to discuss how accounting regulation can influence earnings quality disclosed to the capital market. For this, we considered regulation as a direct determinant of earnings quality and its ability to influence the characteristics of earnings management, conservatism, and timely loss recognition, which are considered earnings quality proxies. The discussion points out that accounting regulation affects earnings quality through its monitoring, standardization, and enforcement roles and that these are complementary. As a monitor, capital market regulators would seek to improve earnings quality, restricting earnings management and favoring conservatism and timely loss recognition. Standardization, such as the adoption of IFRS and SOX, also has these objectives. However, regulation may provide incentives for earnings management due to regulatory scrutiny and adverse political consequences. Finally, the enforcement level, representing the institutional environment, seeks to ensure the application of standards and the fulfillment of the regulation's objective, being an important moderator in determining how regulation would effectively influence earnings quality. Therefore, it is concluded that accounting regulation can influence the quality of accounting information directly and indirectly, but that the effects will not always be uniform in all countries, depending on the level of enforcement.

Keywords: Earnings quality. Accounting regulation. Conservatism. Timely loss recognition. Earnings management.

\section{RESUMEN}

El estudio tuvo como objetivo discutir, teóricamente, cómo la regulación contable puede influir en la calidad de la información contable divulgada al mercado de capitales. Para ello, la regulación fue considerada un determinante directo de la calidad de la información contable, además de su capacidad para incidir en las características de la gestión de resultados, el conservadurismo y el reconocimiento oportuno de pérdidas, consideradas sustitutos de la calidad de la información contable. La discusión señala que la regulación contable afecta la calidad de la información a través de sus roles de monitoreo, estandarización y ejecución, los cuales son complementarios. Como monitor, los reguladores del mercado de capitales buscarían mejorar la calidad de la información contable, restringiendo la gestión de resultados y favoreciendo el conservadurismo y el reconocimiento oportuno de pérdidas. La estandarización, como la adopción de IFRS y SOX, también tiene estos objetivos, pero la regulación puede terminar proporcionando incentivos para la gestión de resultados, debido al escrutinio regulatorio y consecuencias políticas adversas. Finalmente, el nivel de cumplimiento, representativo del entorno institucional, busca asegurar la aplicación de las normas y el cumplimiento del objetivo de la regulación, siendo un moderador importante en la determinación de cómo la regulación influiría efectivamente en la calidad de la información contable. Por tanto, se concluye que la regulación contable es capaz de influir en la calidad de la información contable de forma directa e indirecta, pero que los efectos no siempre serán uniformes en todos los países, ya que dependerá del nivel de cumplimiento.

Palabras-clave: Calidad de la información contable. Regulación de la contabilidad. Conservadurismo. Reconocimiento oportuno de las pérdidas. Gestión de resultados.

\section{INTRODUÇÃO}

A regulação da contabilidade pode ser entendida como um conjunto de leis, normas e princípios, geralmente aceitos, que tratam do conteúdo, da forma e da periodicidade das demonstrações contábeis (Lev, 1988). Assim, a regulação é um fator importante no que tange às informações contábeis, dado que essas sofrem influência do ambiente empresarial e regulatório no qual se encontra uma empresa (Paulo \& Martins, 2007). Além de afetar diretamente práticas contábeis 
que atendam aos anseios dos usuários no tocante à quantidade e qualidade das informações contábeis, a regulação da contabilidade também exerce influência indireta na qualidade, por seu papel na conduta técnica de profissionais da área (Cardoso, Silva, Mario, \& Iudícibus, 2010).

Mais especificamente, a regulação da contabilidade tem como objetivo aumentar a qualidade das normas, para que se possa melhorar a qualidade das informações contábeis fornecidas pelas empresas (Cardoso et al., 2010). Portanto, a regulação da contabilidade tem um papel importante, à medida que afeta as escolhas contábeis e norteia a forma de elaboração e divulgação das informações contábeis fundamentais, para o atendimento das necessidades informacionais dos usuários (Dechow, Ge, \& Schrand, 2010; Cardoso et al., 2010).

Adicionalmente, as informações contábeis de qualidade são necessárias para que a contabilidade cumpra seu papel de prestadora de informações. Com efeito, a qualidade da informação contábil está ligada à sua utilidade para os usuários, tanto que Hendriksen e Van Breda (1999) afirmam que as características qualitativas da informação contábil são definidas como propriedades da informação necessárias para torná-la útil. Dentre essas propriedades, a literatura fornece algumas características para representar a qualidade da informação contábil, como: value relevance (Lang, Raedy, \& Wilson, 2006), gerenciamento de resultados (Burgstahler, Hail, \& Leuz, 2006; Paulo, 2007), reconhecimento oportuno da perda (Dechow et al., 2010) e conservadorismo (Basu, 1997; Ball \& Shivakumar, 2005).

Apesar de a regulação da contabilidade estar voltada ao fornecimento de informações de qualidade, existe uma discussão sobre sua necessidade, que envolve a questão da divulgação obrigatória e voluntária. De um lado, defensores do livre mercado argumentam que as forças econômicas em mercados avançados forneceriam incentivos aos gestores para a divulgação, mesmo na ausência de regulação (Barton \& Waymire, 2004). Por outro lado, o disclosure voluntário pode não ser suficiente para suprir as necessidades informacionais dos usuários, surgindo, assim, a necessidade de intervenção do Estado para corrigir a ausência de informações (Moraes, Gonçalves, \& Niyama, 2015).

Nesse contexto, levanta-se a questão sobre a importância da regulação da contabilidade para a qualidade da informação contábil. Assim, o objetivo do estudo foi analisar, teoricamente, de que maneira a regulação da contabilidade pode afetar a qualidade das informações contábeis divulgadas ao mercado de capitais. Portanto, esta pesquisa é um ensaio teórico e discute a regulação no sentido da divulgação financeira para o mercado de capitais.

O estudo é delimitado por uma combinação de dois fatores: os papeis dos órgãos reguladores e as proxies de qualidade da informação. $O$ primeiro perpassa os diferentes papeis dos órgãos reguladores, que funcionam como monitores, normatizadores e órgãos de enforcement. Cada um desses papeis é discutido a partir de um representante específico, sendo o papel de monitor representado pela importância dos órgãos reguladores do mercado de capitais (como a Comissão de Valores Mobiliários - CVM), as normatizações discutidas a partir da adoção das International Financial Resporting Standards (IFRS) e da Lei Sarbanes-Oxley (SOX), que são as principais normatizações gerais, e o enforcement por meio de características institucionais, como o nível de imposição legal e de proteção aos investidores (que formam um ambiente regulatório que assegura a aplicação das regras).

A segunda delimitação se refere às proxies de qualidade da informação contábil, sendo considerado o gerenciamento de resultados, o conservadorismo e o reconhecimento oportuno das perdas. Assim, além de discutir como a regulação financeira pode influenciar a qualidade das informações contábeis de modo direto, também se analisa como essa gera efeitos nas características qualitativas mais abordadas.

A relevância desta pesquisa se justifica pelo contexto de convergência e normatização contábil, que promovem mudanças na regulação e nas regras contábeis, afetando as informações divulgadas aos usuários. A pesquisa também contribui para a questão levantada por Gordon, Greiner, Kohlbeck, Lin, \& Skaife (2013), que questiona se as leis e regulações são relacionadas com as propriedades da 
informação contábil, além de ser útil para a discussão relacionada à necessidade de divulgação obrigatória ou voluntária. Assim, é relevante para as formulações de órgãos reguladores, demonstrando que a regulação contábil pode influenciar a qualidade de informação divulgada pelas empresas e, consequentemente, o próprio mercado de capitais. Enfim, contribui para a literatura de qualidade da informação contábil, demonstrando que a regulação pode ser considerada uma proxy de qualidade, além de afetar outras características qualitativas, como conservadorismo, gerenciamento de resultados e value relevance.

\section{FUNDAMENTAÇÃO TEÓRICA}

\subsection{Regulação e Livre Mercado}

A fim de fornecer informações contábeis úteis que atendam às necessidades informacionais dos diferentes usuários da contabilidade, a literatura apresenta duas escolas de pensamento: a abordagem do livre mercado e a abordagem regulatória (Sorrentino, Cossu, \& Smarra, 2015). Essas escolas surgem da necessidade ou não da regulação contábil, em que os críticos defendem a existência do livre mercado.

Sob a abordagem do livre mercado, a informação contábil seria um ativo econômico ordinário, que possui oferta e demanda. A demanda pela informação por diferentes usuários, combinada com a oferta das companhias por meio das demonstrações contábeis, resultaria na disseminação eficiente no mercado, sendo a regulação contábil desnecessária (Sorrentino et al., 2015). Assim, a informação contábil teria um preço de equilíbrio, levando em consideração a relação custo-benefício da produção da informação, fazendo com que o mecanismo de mercado pudesse gerar informações suficientes e alcançar um equilíbrio social ótimo (Kam, 1990).

Os argumentos para essa abordagem estão ligados às Teorias da Agência e da Sinalização. Sob a Teoria da Agência, os gestores teriam incentivos para divulgar informações confiáveis voluntariamente, à medida que isso reduziria os custos de monitoramento e, por conseguinte, melhoraria sua reputação e remuneração (Watts \& Zimmerman, 1978; Wolk, Dodd, \& Tearney, 2004). Por sua vez, a Teoria da Sinalização prevê que uma empresa poderia reduzir a incerteza dos investidores ao divulgar voluntariamente informações contábeis, enviando sinais ao mercado (Sorrentino et al., 2015).

Os incentivos para a divulgação voluntária estão relacionados ao aumento da liquidez das ações e à redução nos custos de transação e de capital, o que manteria os investidores interessados na empresa, além da própria competitividade criar essa necessidade (Botosan, 1997; Admati \& Pfleiderer, 2000; Wolk et al., 2004). Ainda, as empresas que tem bom desempenho têm um forte incentivo para divulgar seus resultados e, mesmo que as informações não sejam boas, ainda assim haverá incentivo para a divulgação, pois a não divulgação pode ser percebida pelo mercado como algo pior do que a informação divulgada, consistente com a Teoria de Akerlof sobre o mercado de limões (Akerlof, 1970; Wolk et al., 2004). Enfim, outro argumento em favor de mercados desregulados está relacionado à premissa de que se alguém realmente deseja a informação, pode obtêla por meio de um contrato com a empresa (Wolk et al., 2004).

Por outro lado, os defensores da regulação da contabilidade argumentam que o mecanismo de mercado não é capaz de alcançar um preço de equilíbrio socialmente ótimo para a informação contábil, pois ela é um bem público sobre a qual a empresa tem o monopólio. Portanto, a informação contábil não é igual a outros produtos, já que o consumo por um não exclui a possibilidade de consumo por outro e pode haver o problema de free riders. Dadas essas características da informação contábil, as empresas terão poucos incentivos para produzi-la, o que pode gerar problemas de subprodução (a informação produzida será menor do que a quantidade necessária para as decisões de investimentos) e altos preços para a informação. Portanto, as condições necessárias para uma alocação eficiente dos recursos não serão atendidas, levando à falha do mercado em assegurar uma oferta ótima 
para esse tipo de informação (Kam, 1990; Cooper \& Keim, 1983; Tavares \& Anjos, 2014; Sorrentino et al., 2015).

Nesse contexto, um dos principais motivos para a existência da regulação seriam as falhas de mercado, como as crises econômicas. Com relação a isso, Tavares e Anjos (2014) notam que, muitas vezes, as regulações sobre as práticas contábeis surgem em resposta às crises econômicas, como a que ocorreu em 1929 nos EUA, conhecida pelo crash no mercado de ações. A partir disso houve maior regulação no país, com a criação dos Securities Exchange Acts de 1933 e 1934 para restaurar a confiança do público e dos investidores. Outro exemplo é a crise de 2008, a partir da qual houve mudanças na normatização sobre instrumentos financeiros, com foco na discussão do valor justo (Bushman \& Landsman, 2010). Assim, conforme explica Baldwin e Cave (1999), a regulação é defendida porque o mercado desregulado irá, de alguma forma, falhar em produzir os comportamentos ou resultados de acordo com o interesse público (ótimo social).

Por outro lado, as falhas de mercado também estão ligadas ao fato de que, em um mercado desregulado, as informações negativas dificilmente serão evidenciadas (Dye, 2001). Portanto, a regulação da contabilidade seria necessária para garantir a disseminação das informações contábeis, assegurando que todas as partes tenham o mesmo acesso à informação, além de aumentar a credibilidade das demonstrações contábeis e, consequentemente, a confiança do público no mercado de capitais (Cooper \& Keim, 1983; Tavares \& Anjos, 2014). Assim, conforme Choi e Meek (2011), a regulação da contabilidade estabelece requisitos para garantir que os acionistas recebam informação oportuna, completa e exata.

\subsection{Teoria da Regulação}

A Teoria da Regulação busca justificar os propósitos pelos quais os reguladores ou normatizadores intervêm no comportamento do mercado, além de explicar quem irá receber os benefícios e os encargos da regulação, quais indústrias tem maior chance de serem reguladas, que forma a regulação irá tomar e quais os efeitos da regulação sobre a alocação de recursos (Stigler, 1971; Viscusi, Vernon, \& Harrington, 2005).

Primeiramente, a regulação pode ser entendida como um conjunto de normas coercitivas emanadas do Estado ou órgão regulador, relativas à determinada atividade ou área do conhecimento (Pohlmann \& Alves, 2004). Já para Viscusi et al. (2005), a regulação tem sido definida como uma limitação imposta pelo Estado sobre a discricionariedade que pode ser exercida pelos indivíduos ou organizações, as quais são sustentadas pela ameaça de sanção. Isto é, a regulação está relacionada a intervenção de um órgão regulador em alguma área ou atividade, como na contabilidade.

A regulação pode ser explicada por diversas teorias, havendo três estágios na sua evolução: a Teoria do Interesse Público (ou Análise Normativa como Teoria Positiva), a Teoria da Captura e a Teoria Econômica da Regulação (ou Teoria da Competição entre os Grupos de Interesse) (Viscusi et al., 2005). Apesar dessas teorias serem concorrentes, estudos afirmam que elas podem ser utilizadas de forma complementar para explicar a regulação da contabilidade (Cardoso, Saravia, Tenório, \& Silva, 2009; Niyama, Costa, Dantas, \& Borges, 2011).

\subsubsection{Teoria do Interesse Público}

A Teoria do Interesse Público ou a análise normativa como Teoria Positiva se justifica por duas possibilidades: o sistema de mercado pode ter falhas que devem ser corrigidas por uma intervenção; e pela possibilidade de o mercado adotar uma postura contrária aos interesses sociais (Wolk et al., 2004; Viscusi et al., 2005).

Assim, segundo Stigler (1971), esse ponto de vista é instituído para a proteção e benefício do público em geral, ou para uma grande parte dele. Igualmente, Posner (1974) explica que essa teoria estabelece que a regulação é fornecida em resposta à demanda do público para a correção de práticas de mercado ineficientes ou injustas. Dessa forma, essa teoria prevê que o regulador possui os 
melhores interesses para a sociedade, e regula para gerar o bem-estar social (Tavares \& Anjos, 2014). Em outras palavras, o regulador atua como um agente do interesse público, a fim de alcançar certos resultados publicamente desejados, em circunstâncias nas quais o mercado falharia em fornecer (Baldwin \& Cave, 1999).

Essa teoria presume que o interesse público é bem definido e que os incentivos do regulador são alinhados a ele (Beaver, 1998). Contudo, Baldwin e Cave (1999) ressaltam que é difícil identificar o interesse público, já que a regulação geralmente ocorre no meio de um conflito entre diversas concepções sobre o interesse público. Assim, um dos problemas dessa teoria é que nem todos os usuários têm a mesma necessidade, e que a soma das racionalidades individuais não produz uma racionalidade coletiva (Teorema de Arrow), o que torna difícil identificar e atender o interesse público. Além disso, outra dificuldade está relacionada ao problema de risco moral, uma vez que os reguladores podem ser corrompidos e influenciados a agirem com base no interesse pessoal, ao invés de buscar o bem-estar social (Baldwin \& Cave, 1999; Tavares \& Anjos, 2014).

No contexto contábil, as principais falhas de mercado discutidas na literatura são as externalidades e a assimetria informacional (Kothari, Ramanna, \& Skinner, 2010). Primeiramente, o argumento sobre as externalidades assume que o preço de equilíbrio de um produto não reflete seu verdadeiro custo, o que normalmente ocorre em produtos que necessitam de recursos públicos e/ou em produtos não excludentes (os quais não se pode privar sua utilização). Assim, como as informações contábeis são não excludentes, existe um problema de subprodução de informação (Tavares \& Anjos, 2014). Em segundo lugar, a justificativa de assimetria informacional se aplica em circunstâncias em que os potenciais consumidores de um produto não são informados sobre sua qualidade (Kothari et al., 2010). Nesse contexto, a intervenção governamental pode aumentar o bemestar de todas as partes, tanto dos usuários da informação (público), como dos seus preparadores.

Por fim, essa teoria pode ser utilizada para explicar algumas regulações da contabilidade. Nesse sentido, King (2006) sugere que as normas contábeis emitidas pelo congresso estadunidense em 1933 e 1934 e a Sarbanes-Oxley Act buscaram zelar pelo interesse público. Já no contexto de convergência no Brasil, pode-se observar que algumas alterações das práticas contábeis incorporadas na Lei $n^{\circ} 11.638 / 07$ podem ser explicadas por meio dessa teoria. Assim, a substituição da Demonstração das Origens e Aplicações de Recursos (DOAR) pela Demonstração do Fluxo de Caixa (DFC) e a obrigatoriedade da Demonstração de Valor Adicionado (DVA), bem como a proibição da reavaliação, são exemplos que podem ser explicados pela Teoria do Interesse Público (Cardoso et al., 2009). Contudo, conforme explica Viscusi et al. (2005), as evidências empíricas eram inconsistentes com a Teoria do Interesse Público e, assim, desenvolveu-se a Teoria da Captura.

\subsubsection{Teoria da Captura}

De acordo com Stigler (1971), a política é uma mistura mutável de forças imponderáveis, constantes e imprevisíveis das mais diversas naturezas, que compreendem atos de grande virtude moral e a mais vulgar venalidade. Nesse sentido, a Teoria da Captura diz respeito à ideia de que os reguladores são capturados pelas indústrias que eles deveriam regular, e que acabam servindo os interesses das indústrias ao invés do público (Viscusi et al., 2005). Ou seja, ela presume que as indústrias reguladas tentarão controlar o regulador, já que as decisões tomadas pelo regulador terão um impacto direto em suas atividades (Tavares \& Anjos, 2014).

Sob essa teoria, o principal beneficiário da regulação não é o público, mas aqueles sendo regulados (Beaver, 1998). Dessa maneira, não seria possível alcançar o welfare state, pois os principais beneficiados seriam os agentes de mercado que têm o dever de divulgar suas informações, visto que esses pressionariam os agentes reguladores de tal forma que seus interesses prevaleceriam em relação aos dos demais agentes (Niyama et al., 2011).

No contexto contábil, essa teoria é utilizada para explicar algumas regulações, como a legislação societária (securities acts) nos EUA, na qual os principais beneficiados foram os investidores profissionais e não os investidores individuais de uma forma mais ampla (Cardoso et al., 
2009). Já no contexto de auditoria, Niyama et al. (2011) afirmam que a teoria da captura explica as indefinições com relação à implementação do rodízio de auditores e a descontinuidade. Ou seja, essas regulações parecem ser resultado de ações políticas, representando uma pressão dos agentes que poderiam ter seus trabalhos avaliados.

\subsubsection{Teoria Econômica da Regulação}

Para Viscusi et al. (2005), as duas abordagens anteriores não podem ser consideradas realmente teorias, pois elas não explicam por que e como ocorre a regulação, sendo somente observações empíricas ou hipóteses sobre a regularidade empírica. Em contrapartida, Stigler (1971) desenvolveu a Teoria da Regulação Econômica (ou Teoria do Grupo de Interesse Econômico ou Teoria da Competição entre os Grupos de Interesse), o que lhe concedeu o prêmio Nobel em 1982. O seu trabalho permitiu a construção de uma verdadeira teoria que faz previsões sobre quais indústrias serão reguladas e que forma a regulação irá tomar (Viscusi et al., 2005).

A premissa inicial de Stigler (1971) é que o recurso básico do Estado é o poder de coerção. Assim, um grupo de interesse que consegue convencer o Estado a usar esse poder pode melhorar o seu bem-estar. A outra premissa é que os agentes são racionais no sentido de escolher ações que maximizem sua utilidade. Dessa forma, essas premissas resultam na hipótese de que a regulação é ofertada em resposta a demanda dos grupos de interesse, que agem de forma a aumentar seus ganhos.

A Teoria do Grupo de Interesse Econômico assume que grupos serão formados para proteger interesses econômicos particulares (Tavares \& Anjos, 2014). Nesse sentido, o próprio regulador seria um grupo de interesse - pois ele está preocupado em se manter no poder - que ofereceria regulação na medida desejada por aqueles que podem colaborar com seus objetivos. Portanto, interesses privados irão dominar o processo legislativo, e a regulação irá atender as necessidades do grupo de interesse que exercer maior pressão relativa sobre o regulador e o legislador (Cardoso et al., 2009).

Assim, segundo Niyama et al. (2011, p. 137), essa teoria considera que "o que está em jogo supera os interesses individuais de usuários e operadores, fundamentando-se na busca pela manutenção e domínio de um campo de ação e poder". Portanto, a regulação não está imbuída de espírito público, mas de competição pelo poder, existindo inúmeros grupos de interesses que buscam influenciar os reguladores (lobbying) para que eles protejam seus interesses (Baldwin \& Cave, 1999). Contudo, o grupo de interesse que terá mais chance de ser ouvido será aquele que tiver mais poder e exercer maior pressão no regulador (Cardoso et al., 2009).

A relação entre a regulação da contabilidade e essa teoria pode ser vista por meio do lobbying sobre os reguladores ou normatizadores contábeis, dado que a contabilidade possui consequências econômicas. Assim, posições favoráveis/desfavoráveis serão manifestadas por grupos de interesse quando perceberem que a norma ou a sua alteração trará reflexos em suas atividades (Tavares \& Anjos, 2014). Exemplo disso diz respeito a própria adoção das IFRS, na qual o grupo de interesse influenciado positivamente (investidores estrangeiros, grandes investidores, empresas maiores, multinacionais e grandes empresas de auditoria) tem maior capacidade de exercer pressão sobre o regulador do que empresas menores e nacionais (Cardoso et al., 2009).

\section{POSSÍVEIS INFLUÊNCIAS DA REGULAÇÃO NA QUALIDADE DA INFORMAÇÃO CONTÁBIL}

Para que a contabilidade cumpra seu papel, ela deve prestar informações úteis aos seus usuários, de forma a subsidiar o processo de tomada de decisão. Contudo, como a qualidade dos resultados é contextual, ela significa coisas diferentes para os diferentes usuários das demonstrações contábeis (Dechow \& Schrand, 2004). Entretanto, Schipper e Vincent (2003) entendem que a informação contábil de qualidade é de interesse daqueles que usam as demonstrações contábeis para propósitos contratuais e para decisões de investimento. 
O termo qualidade da informação contábil é vago e difícil de ser definido (Morais \& Curto, 2008), o que resulta na utilização de determinantes para a sua definição. Desse modo, Dechow et al. (2010) revisaram e categorizaram os determinantes da qualidade da informação mais utilizados:

1. Quanto à propriedade dos resultados: persistência dos resultados, modelagem dos accruals normais e anormais, suavização de resultados, reconhecimento assimétrico e oportuno de perdas (conservadorismo e oportunidade) e cumprimento das metas;

2. Quanto à reação dos investidores aos resultados: uso de modelos com significância do retorno/lucro como proxy de qualidade dos resultados, e também para a qualidade do auditor e da governança;

3. Quanto a indicadores externos de erros nos resultados: controles internos fracos, regulação e republicações.

Nesse contexto, a regulação da contabilidade pode influenciar a qualidade da informação contábil de forma indireta, afetando determinantes dos dois primeiros grupos, como o gerenciamento de resultados, conservadorismo e o value relevance, ou de forma direta, como poder ser observado no último grupo de medidas de distorção, em que a própria regulação se torna um determinante da qualidade da informação contábil.

\subsection{A Regulação como Determinante Direta da Qualidade da Informação Contábil}

A regulação como uma característica da qualidade da informação contábil advém do papel de monitor dos órgãos reguladores, que acompanham e alegam resultados distorcidos ou exagerados, identificando empresas com problemas de qualidade na informação (Dechow et al., 2010). Dessa forma, a própria existência de órgãos reguladores do mercado de capitais, como a Comissão de Valores Mobiliários (CVM), auxilia na qualidade da informação contábil divulgada ao mercado e, portanto, no value relevance das informações. Ao exercer o papel de fiscalizador, esses órgãos buscam coibir fraudes e manipulações e assegurar que o público (no caso investidores) tenha acesso às informações das empresas, consistente com a Teoria do Interesse Público.

Esse papel de fiscalizador pode ser visto, por exemplo, no caso das republicações, que também é um dos indicadores externos de qualidade apontado por Dechow et al. (2010), cuja existência aponta a baixa qualidade das informações contábeis. Nesse contexto, Kedia e Rajgopal (2011) apresentam evidências da importância da Securities Exchange Comission (SEC) para a qualidade informacional, mostrando que firmas localizadas mais próximas desse órgão regulador e em áreas com maior atividade de enforcement têm menor probabilidade de republicar suas demonstrações contábeis. Isso ocorre, pois, o escrutínio regulatório da SEC e a aplicação de penalidades por esse órgão faria com que os custos associados à violação dos Princípios de Contabilidade Geralmente Aceitos (PCGA) fossem elevados, o que desencorajaria práticas contábeis agressivas e levaria, portanto, a uma melhor qualidade da informação. No entanto, os autores também observam que a regulação é mais efetiva quando é local, devido às restrições de orçamento, que fazem a SEC investigar firmas que são mais próximas de seus escritórios.

Os órgãos reguladores formam um sistema legal, político e fiscal para o país, desenvolvendo uma configuração institucional que modela os incentivos da firma para divulgar resultados informativos, ou seja, de qualidade (Burgstahler et al., 2006; Soderstrom \& Sun, 2007). Nesse sentido, estudos sugerem algumas características institucionais importantes para a qualidade da informação contábil, como a forte imposição legal e a proteção aos investidores minoritários. A imposição legal está ligada ao papel de enforcement dos órgãos reguladores, ou seja, à sua capacidade de se fazer cumprir as regras legais, enquanto a proteção aos investidores minoritários está relacionada à existência de disposições que os protegem. Assim, a força das leis que protegem os investidores e seu enforcement são estruturas legais complementares, que influenciam a qualidade da informação contábil divulgada ao mercado de capitais (Leuz, Nanda, \& Wysocki, 2003). 
Além de influenciar a qualidade da informação por causa de seu papel no ambiente institucional e de fiscalizador, os órgãos reguladores também influenciam a qualidade da informação contábil por meio de suas ações. Estas se referem à formulação de normatizações, sejam aplicadas às normas contábeis ou aos profissionais responsáveis pela elaboração das informações.

Em relação à normatização contábil, as formulações e decisões de órgãos reguladores estão voltadas à necessidade informacional dos usuários, de modo a atender o interesse público. Por exemplo, ao tornar a adoção das IFRS obrigatória pelas empresas, a regulação impõe algumas características qualitativas da informação, mediante o seguimento do Conceptual Framework do IASB (2018). Essa estrutura estabelece algumas características qualitativas fundamentais (relevância e representação fidedigna) e de melhoria (verificabilidade, comparabilidade, tempestividade e compreensibilidade) que devem ser aplicadas à informação contábil-financeira fornecida pelas demonstrações contábeis ou por outros meios. Dessa forma, os órgãos normatizadores veem a qualidade das demonstrações contábeis como um indicador indireto da qualidade dos próprios padrões contábeis elaborados (Schipper \& Vincent, 2003).

Não obstante, a própria imposição de adoção das IFRS é uma forma que a regulação tem de influenciar a qualidade das informações contábeis, visto que as normas internacionais de contabilidade emitidas pelo International Accounting Standards Board (IASB) estão associadas a uma melhora na qualidade informacional (Barth, Landsman, \& Lang, 2008; Soderstrom \& Sun, 2007; Zeghal, Chtourou, \& Fourati, 2012; Lourenço \& Branco, 2015). Ademais, sua adoção pode ser explicada pela Teoria do Interesse Público, dado que o objetivo do IASB é desenvolver, no interesse público, um conjunto de normas de alta qualidade. Contudo, também é importante frisar que podem existir outras forças que influenciem esse processo normatizador, apesar do objetivo do IASB estar voltado ao público. Por exemplo, estudos demonstram a existência de lobbying em normas emanadas do IASB, condizentes com a Teoria Econômica da Regulação (Bushman \& Landsman, 2010; Hansen, 2011; Carmo, Ribeiro, \& Carvalho, 2016).

Como apontado por Dechow et al. (2010), a regulação da contabilidade também pode afetar diretamente a qualidade da informação por meio dos controles internos. Nesse sentido, outra importante regulação para a qualidade das informações contábeis foi a Lei Sarbanes-Oxley (SOX), principalmente a Seção 404, cujo objetivo era justamente melhorar a qualidade das demonstrações contábeis e aumentar a confiança dos investidores (Iliev, 2010). Condizente com a necessidade de regulação em função das falhas de mercado, a SOX surgiu em resposta a escândalos corporativos e contábeis ocorridos principalmente em 2001, como o caso da Enron. Assim, em 2003, a SEC implementou a Seção 404 da SOX, a qual determinava testes periódicos dos procedimentos de controle interno, assegurando demonstrações contábeis precisas e auxiliando as empresas a detectarem divulgações fraudulentas, a fim de melhorar a confiabilidade e a qualidade das demonstrações.

Nesse contexto, Willekens e Dutillieux (2009) observam que diversos estudos americanos verificaram efeitos significativos na qualidade da informação após a SOX. Contudo, não é só nos EUA que esses efeitos podem ser percebidos. Nesse sentido, os autores argumentam que em ambientes institucionais onde os incentivos para divulgar demonstrações contábeis de alta qualidade são mais fracos do que nos EUA, é provável que haja uma exportação da SOX para melhorar a qualidade da informação contábil.

Em resumo, é possível identificar que a regulação da contabilidade exerce influência sobre a qualidade da informação contábil em função dos papeis que exerce como órgão normatizador, fiscalizador e de enforcement. Isso, por sua vez, é condizente com Leuz e Wysocki (2016), que definem a regulação da divulgação financeira como algo que inclui uma autoridade central, que cria e interpreta formalmente as regras de divulgação, que monitora o atendimento a essas regras e que impõe penalidades para aqueles que desviam dessas. 


\title{
3.2 Influência da Regulação nas Proxies de Qualidade da Informação Contábil
}

A regulação da contabilidade pode ser um determinante direto da qualidade da informação contábil, uma vez que a existência de órgãos reguladores e de regulações como a SOX e as IFRS buscam aumentar a qualidade das informações divulgadas. Não obstante, a regulação da contabilidade também pode afetar a qualidade da informação contábil de maneira indireta, à medida que ela é capaz de influenciar outras proxies, tais quais o gerenciamento de resultados, o conservadorismo e o reconhecimento oportuno das perdas.

\subsubsection{Gerenciamento de Resultados}

Uma das principais preocupações abordadas pela regulação da contabilidade está relacionada ao gerenciamento de resultados, que é uma das proxies mais utilizadas para fazer referência à qualidade da informação contábil (Dechow et al., 2010). Essa preocupação pode ser vista, por exemplo, no discurso do ex-presidente da SEC dos EUA, Arthur Levitt (1998):

\begin{abstract}
As you may know, I recently expressed concern that the motivation to satisfy Wall Street earnings expectations may be overriding common sense business practices. In the process, I fear we are witnessing a gradual, but noticeable erosion in the quality of financial reporting. Many of you, I'm sure, are just as frustrated and concerned about this trend as we, at the SEC, are. It's difficult to hold the line on good practices when competitors operate in the gray area between legitimacy and outright fraud. A gray area where sound accounting practices are perverted; where managers cut corners; and, where earnings reports reflect the desires of management rather than the underlying financial performance of the company.
\end{abstract}

Essa área cinzenta a que Levitt se refere diz respeito à prática de gerenciamento de resultados, que está amparado por princípios e padrões contábeis (Niyama, Rodrigues, \& Rodrigues, 2015). O gerenciamento de resultados é definido por Schipper (1989) como uma intervenção intencional no processo do relatório financeiro externo, com a intenção de obter um ganho particular. Por sua vez, Healy e Wahlen (1999) dizem que o gerenciamento de resultados ocorre quando os administradores usam julgamento sobre relatórios financeiros e estruturam operações para alterar esses relatórios, seja para enganar alguns investidores sobre o desempenho econômico da empresa, ou para influenciar resultados contratuais que dependem dos números contábeis reportados.

Os reguladores consideram o gerenciamento de resultados como algo difundido e problemático, tanto que o objetivo da SEC é melhorar a qualidade da informação contábil por meio da redução do gerenciamento de resultados (Dechow \& Skinner, 2000). Essa redução seria alcançada (i) pelo papel da regulação como agente fiscalizador, (ii) pela sua importância para formar um ambiente institucional favorável (enforcement) e (iii) a partir das regulações exigidas (normatizador). Portanto, os mesmos pontos destacados na seção anterior, no que se refere à qualidade da informação de modo direto, podem ser destacados de forma indireta, por meio de seu impacto no gerenciamento de resultados.

Primeiramente, um dos principais papeis da regulação da contabilidade, como o da SEC, é coibir fraudes e manipulações nas informações divulgadas (Kedia \& Rajgopal, 2011), consistente com seu papel de fiscalizador. Em segundo lugar, o enforcement pode ser visto por meio da formação de um ambiente institucional efetivo na restrição do gerenciamento de resultados, sendo a imposição legal e a proteção aos investidores as características institucionais mais evidentes para isso. Nesse sentido, estudos demonstram que empresas situadas em países com forte imposição legal e forte proteção aos investidores apresentam menor nível de gerenciamento de resultados (Leuz et al., 2003; Haw, Hu, Hwang, \& Wu, 2004; Lang et al., 2006; Burgstahler et al., 2006; Francis \& Wang, 2008). Leuz et al. (2003) explicam que a forte proteção legal afeta a qualidade das informações, pois ela limita a aquisição de benefícios de controle privados e, consequentemente, mitiga os incentivos para gerenciar os resultados. Em terceiro lugar, as normatizações exigidas pelos órgãos reguladores 
também são capazes de restringir o gerenciamento de resultados, como é o caso das IFRS e da SOX, que são as principais estudadas.

A SOX é uma regulação que impacta o gerenciamento de resultados, devido principalmente às suas disposições acerca dos sistemas de controle interno, auditoria e governança, e que visa restaurar a integridade das demonstrações contábeis, ao limitar o gerenciamento de resultados e as fraudes contábeis. Consistente com isso, estudos demonstram que a regulação da SOX ajudou a reduzir as manipulações dos resultados, aumentando a qualidade das informações contábeis (Cohen, Dey, \& Lys, 2008; Zhou, 2008; Aubert \& Grudnitski, 2014).

No entanto, Cohen et al. (2008) fornecem evidências adicionais sobre esse impacto, observando que o gerenciamento baseado nos accruals aumentou desde 1987 até a passagem da SOX (em 2002), seguido de um declínio. Por outro lado, verificaram que o nível de gerenciamento real (por decisões operacionais) diminuiu antes da SOX e aumentou significativamente após a sua passagem, o que sugere que as empresas passaram do gerenciamento de resultados baseado nos accruals para o gerenciamento real. Dessa maneira, nota-se a classificação do gerenciamento de resultados em dois grupos: o de accruals e o real. O primeiro procura alterar as políticas e estimativas contábeis, interferindo nos accruals discricionários, enquanto o segundo interfere diretamente no fluxo de caixa das empresas, em que os recursos podem ser aplicados em projetos duvidosos que geram desconfiança da viabilidade dos negócios (Almeida, 2010).

Quanto às IFRS, a adoção de padrões de maior qualidade restringiria o gerenciamento de resultados. Consistente com isso, Barth et al. (2008) observam que empresas que adotam as normas internacionais de contabilidade geralmente apresentam menor gerenciamento de resultados do que as que adotam as normas locais. Cai, Rahman e Courtenay (2008) também verificam que o gerenciamento de resultados em países que adotaram as IFRS tem diminuído, e que países com forte imposição legal apresentam menor gerenciamento. Outros estudos também corroboram essa redução no gerenciamento de resultados por accruals após a adoção das IFRS, como Zeghal, Chtourou e Sellami (2011), Ho, Liao e Taylor (2015) e Ipino e Parbonetti (2016).

Por outro lado, Niyama, Rodrigues e Rodrigues (2015) ressaltam que as normas internacionais de contabilidade emitidas pelo IASB têm influência anglo-saxônica, na qual predomina a essência sobre a forma e o sistema baseado em princípios. Assim, nem todos os padrões e critérios são detalhados, não alcançando todas as situações possíveis e permitindo julgamentos dos gestores (Matsumoto \& Parreira, 2009; Niyama et al., 2015). Assim, como as IFRS são baseadas em princípios, isso daria flexibilidade e poderia gerar um aumento no gerenciamento de resultados (Ugrin, Mason, \& Emley (2017), o que é observado a partir das evidências empíricas de alguns estudos (Callao \& Jarne, 2010; Liu, Yip Yuen, Yao, \& Chan, 2014; Capkun, Collins, \& Jeanjean, 2016).

Como a normatização relacionada à adoção das IFRS apresenta evidências contraditórias sobre seu impacto no gerenciamento de resultados, pode ser que haja algumas características institucionais por trás dessa relação (Ugrin et al., 2017). Esse é o caso da regulação relacionada à proteção legal, sendo a imposição legal uma característica importante para frear o gerenciamento de resultados (Leuz et al., 2003; Haw et al., 2004; Lang et al., 2006; Burgstahler et al., 2006; Francis \& Wang, 2008). Portanto, o impacto da regulação no gerenciamento de resultados não dependeria somente das normas que são exigidas, mas também do papel de enforcement exercido pelos órgãos reguladores.

Apesar de buscar o aumento da qualidade da informação, principalmente por meio da redução de práticas contábeis agressivas e manipulações, as normatizações da regulação podem acabar fornecendo incentivos para a prática de gerenciamento de resultados. Isso pode ser visto a partir dos incentivos elencados por Martinez (2001), que classifica-os basicamente em: motivações vinculadas ao mercado de capitais, motivações contratuais e motivações regulamentares e custos políticos, o qual aponta a possibilidade de regulações induzirem o gerenciamento de resultados e, consequentemente, piorarem a qualidade dos lucros. 
Conforme Healy e Wahlen (1999), essas motivações regulamentares podem ser classificadas, ainda, como gerenciamento de resultados para contornar as regulações das indústrias, reduzir o risco de investigação e de intervenção antitruste por parte dos reguladores e para fins de planejamento tributário. Nesse contexto, as empresas gerenciariam resultados com o intuito de parecer menos lucrativas, a fim de evitar o desgaste e inveja de outros setores, que poderiam alegar práticas de mercado injustas e gerenciar restrições regulatórias (Healy \& Wahlen, 1999; Martinez, 2001). Visto que a regulação econômica existe em resposta às falhas de mercado como monopólio e lucros excessivos, os reguladores devem preservar o jogo justo de mercado e, por isso, fiscalizar as empresas para assegurar essas práticas justas (Tavares \& Anjos, 2014). Assim, as firmas acabam gerenciando resultados para evitar o escrutínio dos reguladores e consequências políticas adversas, por exemplo, quando apresentam lucros excessivos. Nesse caso, a existência de regulação acabaria incentivando o gerenciamento de resultados para baixo, a fim de evitar alegações de práticas de mercado injustas.

Dechow et al. (2010) elencam estudos que documentam que as empresas se engajam em gerenciamento de resultados quando os lucros são capazes de gerar intervenções regulatórias custosas ou consequências políticas para a empresa. Esse é o caso, por exemplo, da exigência de capital regulatório no setor bancário, que leva os bancos a gerenciarem resultados, a fim de atender essa exigência (Barth, Gomez-Biscarri, Kasznik, \& López-Espinosa, 2017). Outro exemplo é a constrição no regime regulatório, como a causada pela adoção das IFRS e da SOX, que torna o gerenciamento por accruals mais oneroso e leva a um aumento no gerenciamento de resultados real (Cohen et al. 2008; Ho et al., 2015; Ipino \& Parbonetti, 2016). Outros exemplos podem ser vistos em regulações de indústrias específicas, que acabam levando as empresas a gerenciar resultados por causa dos custos políticos (ver por exemplo Cahan, Chavis e Elmendorf (1997) e Key (1997)).

Por fim, é importante destacar que para uma informação contábil ser de qualidade, não é necessário que o gerenciamento de resultados seja extinto, mas reduzido. Dechow e Skinner (2000) afirmam que a inexistência de gerenciamento de resultados não é uma solução ótima, pois é necessária devido à indispensabilidade de estimativas e julgamentos para implementar a contabilidade por competência. Assim, ao se eliminar toda a flexibilidade, eliminar-se-ia também a utilidade dos resultados.

Nesse contexto, destaca-se que os accruals discricionários são usados como proxy do gerenciamento de resultados, e que alguns estudos consideram que esses accruals carregam informação e, portanto, aumentam a qualidade da informação (Ewert \& Wagenhofer, 2015). Dessa forma, existem duas visões na literatura: a do gerenciamento de resultados que melhora a qualidade da informação contábil, e a que deteriora, dependendo dos motivos por trás dele (Mussalo, 2015). Nesse sentido, Healy e Palepu (2001) explicam que a divulgação pode refletir tanto motivações oportunistas como motivações informacionais (sinalização). Assim, o gerenciamento de resultados decorrente de motivações pessoais ou oportunistas reduziria a qualidade da informação contábil, enquanto o gerenciamento no sentido de aumentar a informatividade e a eficiência na comunicação de informações privadas sobre o desempenho da empresa aumentaria a utilidade (Dechow, 1994; Tucker \& Zarowin, 2006; Mussalo, 2015).

Enfim, nota-se que a regulação da contabilidade pode ser um motivador para a existência de gerenciamento de resultados, já que as empresas tentam parecer menos lucrativas para chamarem menos atenção dos reguladores. Por outro lado, a regulação da contabilidade também pode auxiliar na redução do gerenciamento de resultados, sendo a forte imposição legal uma característica importante para isso. Portanto, a regulação pode gerar ambos os efeitos, melhorando ou piorando a qualidade das informações contábeis sob o aspecto do gerenciamento de resultados.

\subsubsection{Conservadorismo e Reconhecimento Oportuno das Perdas}

A ideia do conservadorismo é fornecer informações mais confiáveis por meio de demonstrações que não sejam muito otimistas (Lopes, 2002). Dessa maneira, o conservadorismo consiste em um importante instrumento para os usuários das informações contábeis, já que ele limita 
as ações dos gestores e aumenta a confiabilidade dos números divulgados (Paulo, 2007). Assim, conforme Dechow et al. (2010), o mercado de capitais percebe o conservadorismo como um determinante que melhora a qualidade da informação.

O conservadorismo contábil, segundo Bliss (1924 apud Basu, 1997), é expresso na tradicional regra utilizada por contadores que prevê a antecipação das perdas e a não antecipação dos lucros. Já para Basu (1997), o conservadorismo é a tendência que os contadores têm de pedir um maior grau de verificação para reconhecer boas notícias como ganhos do que para reconhecer as más notícias como perdas. Ou seja, o conservadorismo é uma verificação assimétrica exigida pelos ganhos e pelas perdas (Watts, 2003), que geralmente reflete as más notícias mais rapidamente do que as boas notícias. Logo, o conservadorismo está ligado ao reconhecimento oportuno das perdas, já que ele visa o reconhecimento mais tempestivo das más notícias.

Por outro lado, a qualidade da informação contábil também deveria estar relacionada à representação fidedigna e não viesada (neutra) das transações e eventos (Paulo, 2007), o que não é totalmente alcançado com a prática do conservadorismo, uma vez que as perdas serão reconhecidas mais oportunamente do que os ganhos. Contudo, a falta de verificabilidade, associada com o conservadorismo, leva a Contabilidade a divulgar informações de forma assimétrica, incorporando os maus resultados mais rapidamente. Dessa forma, Paulo (2007) conclui que o conservadorismo e a neutralidade devem ser entendidos em termos de benefícios e malefícios, de forma a atingir os objetivos das demonstrações contábeis.

O conservadorismo está presente na contabilidade há muito tempo, devido à própria regulação, que é uma das razões para sua existência (Basu, 1997; Watts, 2003). Notadamente, Watts (2003) explica que os órgãos normatizadores e reguladores, como a SEC, têm incentivos para favorecer o conservadorismo, pois esse reduz os custos políticos impostos sobre os órgãos. Esse incentivo está relacionado à assimetria no custo dos reguladores, que enfrentariam mais críticas se as empresas superestimassem os ativos líquidos do que se os subestimassem (já que as perdas por superavaliação seriam mais observáveis e utilizáveis no processo político, do que os ganhos perdidos por subavaliação). Assim, como a regulação tem um incentivo para evitar a percepção de responsabilidade pelas perdas dos investidores, os órgãos reguladores promoveriam a divulgação oportuna das más notícias (Ball, Kothari, \& Robin, 2000).

Entretanto, deve-se considerar que diversos estudos consideram a existência de dois tipos de conservadorismo: condicional e incondicional. Segundo Beaver e Ryan (2005), o conservadorismo condicional (conservadorismo ex post ou dependente das notícias) significa que os valores contábeis podem ser diminuídos sob circunstâncias adversas, mas não podem ser aumentados em circunstâncias favoráveis, sendo o último de comportamento conservador. Já o conservadorismo incondicional (conservadorismo ex ante ou independente de notícias) é definido como a subavaliação sistemática do patrimônio, independente dos sinais de prováveis perdas econômicas (Dantas, Paulo, \& Medeiros, 2013). Ou seja, ele tem seu propósito no princípio da prudência e já está incorporado nas operações contábeis das empresas (Rodrigues, 2012). Nesse sentido, diversos autores argumentam que a regulação induz o conservadorismo na sua forma incondicional (Ball, 2001; Ball \& Shivakumar, 2005; Qiang, 2007), uma vez que esse não depende de notícias e nem de sinais de prováveis perdas econômicas.

Embora existam incentivos regulatórios para a contabilidade ser conservadora, ocasionalmente os normatizadores contábeis parecem ignorar esses incentivos (Watts, 2003). Exemplo disso é a norma americana SFAS 142 do FASB, que substitui a amortização do goodwill pelo teste de imparidade. Segundo Watts (2003), essa substituição ocorreu logo após uma apresentação dos bancos de investimento para o FASB, o que sugere a existência de lobbying sobre essa regulação. Portanto, a SFAS 142 não favorece o conservadorismo, e ela pode ter sido resultado da pressão de um grupo de interesse (Teoria Econômica da Regulação). Outro exemplo pode ser visto na discussão relacionada à prudência, que foi retirada da Estrutura Conceitual do IASB em 2010 por 
ser inconsistente com a neutralidade, mas que, na revisão feita em 2018, voltou a compor a Estrutura Conceitual com um conceito de prudência cautelosa, que não esclareceu o suficiente.

Mesmo que algumas normas individuais não propiciem efetivamente o conservadorismo, a normatização dos órgãos reguladores busca o aumento da qualidade da informação contábil por meio dessa determinante. No contexto da normatização relacionada às IFRS, isso é corroborado por André, Filip e Paugam (2015), que argumentam que as normas internacionais são conceitualmente conservadoras, apesar de que a aplicação inadequada dos princípios do conservadorismo condicional pode impedir que os relatórios financeiros atinjam o nível de conservadorismo almejado pelo IASB. Empiricamente, alguns estudos observam que a adoção das IFRS permitiu o reconhecimento mais oportuno das perdas, havendo um aumento no conservadorismo contábil em diversos países (Barth et al., 2008; Zhang, 2011), enquanto outros identificaram uma redução (André et al., 2015; Zeghal \& Lahmar, 2016).

Quadro 1: Resumo das principais influências da regulação na qualidade das informações contábeis

\begin{tabular}{|c|c|c|c|c|}
\hline $\begin{array}{l}\text { Papel da regulação } \\
\text { da contabilidade }\end{array}$ & $\begin{array}{l}\text { Representante } \\
\text { no estudo }\end{array}$ & $\begin{array}{c}\text { Regulação como } \\
\text { determinante direta }\end{array}$ & $\begin{array}{l}\text { Gerenciamento de } \\
\text { Resultados }\end{array}$ & $\begin{array}{c}\text { Conservadorismo ou } \\
\text { Reconhecimento } \\
\text { oportuno das perdas }\end{array}$ \\
\hline $\begin{array}{l}\text { Monitor } \\
\text { "Ser" - existência } \\
\text { do regulador para } \\
\text { monitorar/fiscalizar }\end{array}$ & $\begin{array}{l}\text { Órgão regulador } \\
\text { do mercado de } \\
\text { capitais (SEC) }\end{array}$ & $\begin{array}{l}\text { O objetivo dos órgãos } \\
\text { reguladores é melhorar a } \\
\text { qualidade das } \\
\text { informações contábeis e } \\
\text { o acesso a essas. }\end{array}$ & $\begin{array}{l}\text { Um dos principais } \\
\text { papeis dos reguladores é } \\
\text { coibir fraudes e } \\
\text { manipulações nas } \\
\text { informações contábeis. }\end{array}$ & $\begin{array}{l}\text { Órgãos reguladores } \\
\text { possuem incentivos para } \\
\text { favorecer o } \\
\text { conservadorismo, por } \\
\text { causa dos custos } \\
\text { políticos. }\end{array}$ \\
\hline $\begin{array}{l}\text { Normatizador } \\
\text { "Agir" - regulação } \\
\text { para criar ou } \\
\text { endossar normas }\end{array}$ & IFRS e SOX & $\begin{array}{l}\text { As normatizações } \\
\text { buscam melhorar a } \\
\text { qualidade da informação } \\
\text { contábil, por exemplo, } \\
\text { aumentando a } \\
\text { confiabilidade. }\end{array}$ & $\begin{array}{l}\text { Apesar das } \\
\text { normatizações buscarem } \\
\text { a redução no } \\
\text { gerenciamento de } \\
\text { resultados, a regulação } \\
\text { pode se tornar um } \\
\text { incentivo para essa } \\
\text { prática, devido o } \\
\text { escrutínio regulatório e } \\
\text { consequências políticas } \\
\text { adversas. }\end{array}$ & $\begin{array}{l}\text { As normatizações } \\
\text { favorecem o } \\
\text { conservadorismo a fim } \\
\text { de reduzir a incerteza e } \\
\text { aumentar a } \\
\text { confiabilidade. }\end{array}$ \\
\hline $\begin{array}{l}\text { Enforcement } \\
\text { "Reagir" - } \\
\text { regulação para } \\
\text { impor as normas }\end{array}$ & $\begin{array}{c}\text { Ambiente } \\
\text { institucional } \\
\text { caracterizado } \\
\text { pela imposição } \\
\text { legal e proteção } \\
\text { aos investidores }\end{array}$ & $\begin{array}{l}\text { A força das leis que } \\
\text { protegem os investidores } \\
\text { e seu enforcement são } \\
\text { estruturas legais } \\
\text { complementares que } \\
\text { influenciam a qualidade } \\
\text { da informação contábil } \\
\text { divulgada ao mercado de } \\
\text { capitais. }\end{array}$ & $\begin{array}{l}\text { O gerenciamento de } \\
\text { resultados é menor em } \\
\text { países com forte } \\
\text { imposição legal e } \\
\text { proteção aos } \\
\text { investidores, pois essas } \\
\text { características limitam a } \\
\text { aquisição de benefícios } \\
\text { privados e os incentivos } \\
\text { para gerenciar } \\
\text { resultados. }\end{array}$ & $\begin{array}{l}\text { As empresas são mais } \\
\text { conservadoras em } \\
\text { ambientes de maior } \\
\text { enforcement. }\end{array}$ \\
\hline
\end{tabular}

Fonte: Elaborado pelos autores

A regulação da SOX também é uma normatização importante que aumenta o uso de relatórios financeiros mais conservadores, visto o maior nível de monitoramento e exposição ao risco de litígio sob essa regulação (He, El-Masry, Wu, 2008). Lobo e Zhou (2006) constataram que houve um aumento no conservadorismo das demonstrações contábeis após a SOX e que as empresas reconheceram as perdas mais oportunamente, concluindo que essa regulação ajudou a alterar a discricionariedade do comportamento de divulgação dos gestores, tornando-o mais conservador. Mitra, Jaggi e Hossain (2013) também verificaram que as empresas americanas que tinham um controle interno fraco passaram a exibir maior conservadorismo após a passagem da SOX, sugerindo 
que o maior escrutínio regulatório levou a um maior conservadorismo, como forma de reduzir a incerteza na divulgação e aumentar a confiabilidade da informação.

Além das normatizações, a regulação também influencia o conservadorismo por meio do enforcement, sendo as empresas mais conservadoras em ambientes com maior nível de proteção aos acionistas e pressão legal (Basu, 1997; He et al., 2008; Bushman \& Piotroski, 2006). Por exemplo, Bushman e Piotroski (2006) verificaram que as empresas em países com forte enforcement público (caracterizado por um aplicador público independente e poderoso) retardavam o reconhecimento de boas notícias em comparação a empresas em países com enforcement público fraco. Além disso, o reconhecimento das perdas era mais oportuno em países com forte proteção ao investidor e alta qualidade no sistema judicial. Outra evidência pode ser vista no estudo de Jayaraman (2012), que observou que o enforcement dos países, representado pela adoção inicial das leis de informação privilegiada, estava associado a um aumento significativo no reconhecimento oportuno das perdas.

Em suma, a regulação da contabilidade, de uma forma geral, é capaz de influenciar a determinante de conservadorismo contábil, contribuindo positivamente para a qualidade da informação contábil. Essa contribuição se mostra tanto no seu papel de órgão fiscalizador, havendo incentivos para buscarem informações mais conservadoras, quanto no seu papel de normatizador e de enforcement. Por fim, as discussões sobre o impacto da regulação da contabilidade na qualidade das informações contábeis podem ser sumarizadas conforme o Quadro 1.

\section{CONSIDERAÇÕES FINAIS}

O objetivo do estudo foi discutir as principais influências da regulação da contabilidade sobre a qualidade da informação contábil divulgada nos relatórios financeiros. Essa discussão foi realizada levando em consideração os diferentes papeis exercidos pelos órgãos reguladores (monitor, normatizador e enforcement) e algumas proxies utilizadas para determinar a qualidade da informação (gerenciamento de resultados, conservadorismo e reconhecimento oportuno das perdas). Como a regulação da contabilidade é um assunto amplo, a discussão se baseia nos órgãos reguladores do mercado de capitais (representando o papel de monitor), nas normatizações relacionadas às IFRS e SOX, que foram as mais marcantes (papel de normatizador) e nas características institucionais relacionadas à imposição legal e proteção aos investidores (papel de enforcement).

Os diferentes papeis da regulação são integrativos e complementares na busca por maior qualidade da informação. O papel de monitor demonstra o objetivo primordial da regulação como mecanismo que melhora a quantidade e qualidade das informações contábeis, seja de modo direto ou indireto, por meio da busca de informações mais conservadoras e menos gerenciadas. Mas, para atender esse objetivo, as normatizações e o enforcement também devem ter a qualidade necessária para assegurar informações contábeis de qualidade. Nesse ponto, também é discutido que o maior enforcement está associado a informações de maior qualidade, menos gerenciadas e mais conservadoras. Assim, a principal questão está nas normatizações exigidas pelos órgãos reguladores e na sua capacidade de conseguir atender os objetivos da regulação, no que tange à qualidade informacional.

Ao avaliar as normatizações, com foco nas IFRS e SOX, é possível identificar que essas influenciam positivamente a qualidade das informações contábeis, buscando limitar o gerenciamento de resultados e aumentar o conservadorismo. No entanto, a regulação pode acabar fornecendo incentivos para o gerenciamento de resultados, por causa do escrutínio regulatório e consequências políticas adversas. Além disso, a discricionariedade permitida pelas normas internacionais de contabilidade também pode conceder espaço ao gerenciamento de resultados. Portanto, a regulação da contabilidade pode ser um incentivador ou um inibidor para a prática de gerenciamento de resultados, sendo o enforcement uma característica institucional importante para determinar esse efeito. Assim, não é possível dizer que a regulação da contabilidade irá afetar a qualidade da informação de maneira uniforme em todos os países. 
A pesquisa busca contribuir para a literatura de regulação da contabilidade e qualidade da informação, demonstrando que a regulação pode ser um determinante direto e indireto da qualidade, influenciando o gerenciamento de resultados, o conservadorismo e o reconhecimento oportuno das perdas. Também se diferencia de estudos anteriores, ao considerar os diferentes papeis da regulação da contabilidade, mostrando sua interconexão e complementariedade. No entanto, o estudo se limita à literatura contábil sobre a regulação da divulgação financeira de uma forma geral - como IASB, IFRS, SOX -, não focando em padrões específicos. Ao avaliar normatizações específicas, é possível que essas tenham efeitos divergentes sobre a qualidade da informação contábil e que sejam explicadas por teorias concorrentes da regulação. Assim, sugere-se que estudos futuros analisem os efeitos de regulações específicas sobre a qualidade da informação contábil, bem como considerem outros determinantes para tal, como a persistência e as republicações.

\section{REFERÊNCIAS}

Admati, A. R., \& Pfleiderer, P. (2000). Forcing Firms to Talk: Financial Disclosure Regulation and Externalities. Review of Financial Studies, 13(3), 479-519. doi:10.1093/rfs/13.3.479

Akerlof, G. (1970). The market for lemons: Qualitative uncertainty and the market mechanism, Quarterly Journal of Economics, 84, 488- 500.

Almeida, J. E. F.(2010). Qualidade da informação contábil em ambientes competitivos. 2010. 188f. Tese (Doutorado em Contabilidade). Programa de Pós Graduação em Ciências Contábeis, Universidade de São Paulo, São Paulo.

André, P., Filip, A., \& Paugam, L. (2015). The effect of mandatory IFRS adoption on conditional conservatism in Europe. Journal of Business Finance \& Accounting, 42(3-4), 482-514.

Aubert, F., \& Grudnitski, G. (2014). The impact of SOX on opportunistic management behavior. International Review of Financial Analysis, 32, 188-198.

Baldwin, R. \& Cave, Martin (1999). Understanding regulation. Oxford University Press.

Ball, R. (2001). Infrastructure requirements for an economically efficient system of public financial reporting and disclosure. Brookings-Wharton papers on financial services, 2001(1), 127-169.

Ball, R., Kothari, S. P., \& Robin, A. (2000). The effect of international institutional factors on properties of accounting earnings. Journal of Accounting and Economics, 29(1), 1-51.

Ball, R., \& Shivakumar, L. (2005). Earnings quality in UK private firms: comparative loss recognition timeliness. Journal of Accounting and Economics, 39(1), 83-128.

Barth, M. E., Gomez-Biscarri, J., Kasznik, R., \& López-Espinosa, G. (2017). Bank earnings and regulatory capital management using available for sale securities. Review of Accounting Studies, 22(4), 17611792.

Barth, M. E., Landsman, W. R., \& Lang, M. H. (2008). International accounting standards and accounting quality. Journal of Accounting Research, 46(3), 467-498.

Barton, J., \& Waymire, G. (2004). Investor protection under unregulated financial reporting. Journal of Accounting and Economics, 38, 65-116.

Basu, S. (1997). The conservatism principle and the asymmetric timeliness of earnings1. Journal of Accounting and Economics, 24(1), 3-37.

Beaver, W. (1998). Financial reporting: An accounting revolution (3rd ed.). Upper Saddle River, NJ: Prentice Hall.

Beaver, W. H., \& Ryan, S. G. (2005). Conditional and unconditional conservatism: Concepts and modeling. Review of Accounting Studies, 10(2-3), 269-309.

Botosan, C. A. (1997). Disclosure level and the cost of equity capital. Accounting review, 323-349.

Burgstahler, D. C., Hail, L., \& Leuz, C. (2006). The importance of reporting incentives: Earnings management in European private and public firms. The Accounting Review, 81(5), 983-1016.

Bushman, R., \& Landsman, W. R. (2010). The pros and cons of regulating corporate reporting: A critical review of the arguments. Accounting and Business Research, 40(3), 259-273.

Bushman, R. M., \& Piotroski, J. D. (2006). Financial reporting incentives for conservative accounting: The influence of legal and political institutions. Journal of Accounting and Economics, 42(1-2), 107-148. 
Cahan, S. F., Chavis, B. M., \& Elmendorf, R. G. (1997). Earnings management of chemical firms in response to political costs from environmental legislation. Journal of Accounting, Auditing \& Finance, 12(1), 37-65.

Cai, L., Rahman, A. R., \& Courtenay, S. M. (2008). The effect of IFRS and its enforcement on earnings management: An international comparison. Available at SSRN 1473571.

Callao, S., \& Jarne, J. (2010). Have IFRS affected earnings management in the European Union? Accounting in Europe, 7(2), 159-189.

Capkun, V., Collins, D., \& Jeanjean, T. (2016). The effect of IAS/IFRS adoption on earnings management (smoothing): A closer look at competing explanations. Journal of Accounting and Public Policy, 35(4), 352-394

Cardoso, R. L., Saravia, E., Tenório, F. G., \& Silva, M. A. (2009). Regulação da contabilidade: teorias e análise da convergência dos padrões contábeis brasileiros aos IFRS. Revista de Administração Pública, 43(4), 773-799.

Cardoso, R. L., Silva, M. A., do Carmo Mário, P., \& De Iudícibus, S. (2010). Análise da regulação da contabilidade à luz da teoria tridimensional do direito de Miguel Reale. Revista Universo Contábil, 6(1), 06-27.

Carmo, C. H. S., Ribeiro, A. M., \& de Carvalho, L. N. G. (2016). Lobbying na regulação contábil: desenvolvimentos teóricos e pesquisas empíricas. Revista Universo Contábil, 12(2), 59-79.

Choi, F. D. \& Meek, G. K. (2011). International accounting. Pearson Higher Ed.

Cohen, D. A., Dey, A., \& Lys, T. Z. (2008). Real and accrual-based earnings management in the pre-and post-Sarbanes-Oxley periods. The Accounting Review, 83(3), 757-787.

Cooper, K., \& Keim, G. D. (1983). The economic rationale for the nature and extent of corporate financial disclosure regulation: A critical assessment. Journal of Accounting and Public Policy, 2(3), 189-205.

Dantas, J. A.; Paulo, E.; Medeiros, O. R. (2013). Conservadorismo condicional na indústria bancária brasileira em situações de maior percepção de risco. Revista Universo Contábil, 9(2), 83-103.

Dechow, P. M. (1994). Accounting earnings and cash flows as measures of firm performance: The role of accounting accruals. Journal of Accounting and Economics, 18(1), 3-42.

Dechow, P. M., \& Skinner, D. J. (2000). Earnings management: Reconciling the views of accounting academics, practitioners, and regulators. Accounting Horizons, 14(2), 235-250.

Dechow, P., Ge, W., \& Schrand, C. (2010). Understanding earnings quality: A review of the proxies, their determinants and their consequences. Journal of Accounting and Economics, 50(2-3), 344-401.

Dechow, P. \& Schrand, C. M. (2004). Earnings quality. Charlottesville: CFA Institute.

Dye, R. A. (2001). An evaluation of "essays on disclosure" and the disclosure literature in accounting. Journal of Accounting and Economics, 32(1-3), 181-235.

Ewert, R., \& Wagenhofer, A. (2015). Economic relations among earnings quality measures. Abacus, 51(3), 311-355.

Francis, J. R., \& Wang, D. (2008). The joint effect of investor protection and Big 4 audits on earnings quality around the world. Contemporary Accounting Research, 25(1), 157-191.

Gordon, E. A., Greiner, A., Kohlbeck, M. J., Lin, S., \& Skaife, H. (2013). Challenges and opportunities in cross-country accounting research. Accounting Horizons, 27(1), 141-154.

Hansen, T. B. (2011). Lobbying of the IASB: An Empirical Investigation. Journal of International Accounting Research, 10(2), 57-75.

Haw, I. M., Hu, B., Hwang, L. S., \& Wu, W. (2004). Ultimate ownership, income management, and legal and extra-legal institutions. Journal of Accounting Research, 42(2), 423-462.

He, H., El-Masry, E.-H., \& Wu, Y. (2008). Accounting conservatism of cross-listing firms in the pre- and post-Sarbanes Oxley periods. Advances in Accounting, 24(2), 237-242.

Healy, P. M., \& Palepu, K. G. (2001). Information asymmetry, corporate disclosure, and the capital markets: A review of the empirical disclosure literature. Journal of Accounting and Economics, 31(1-3), 405440.

Healy, P. M., \& Wahlen, J. M. (1999). A review of the earnings management literature and its implications for standard setting. Accounting Horizons, 13(4), 365-383.

Hendriksen, E. S. \& Breda, M. F. (1999). Teoria da contabilidade. São Paulo: Atlas.

Ho, L. C. J., Liao, Q., \& Taylor, M. (2015). Real and accrual-based earnings management in the pre-and post-IFRS periods: Evidence from China. Journal of International Financial Management \& Accounting, 26(3), 294-335. 
Iliev, P. (2010). The effect of SOX Section 404: Costs, earnings quality, and stock prices. The Journal of Finance, 65(3), 1163-1196.

Ipino, E., \& Parbonetti, A. (2016). Mandatory IFRS adoption: the trade-off between accrual-based and real earnings management. Accounting and Business Research, 47(1), 91-121.

Jayaraman, S. (2012). The effect of enforcement on timely loss recognition: Evidence from insider trading laws. Journal of Accounting and Economics, 53(1-2), 77-97.

Kam, V. (1990). Accounting theory. New York: Wiley.

Kedia, S., \& Rajgopal, S. (2011). Do the SEC's enforcement preferences affect corporate misconduct?. Journal of Accounting and Economics, 51(3), 259-278.

Key, K. G. (1997). Political cost incentives for earnings management in the cable television industry. Journal of Accounting and Economics, 23(3), 309-337.

King, T. A. (2006). More than a numbers game: a brief history of accounting. Jew Jersey:

Wiley.

Kothari, S. P., Ramanna, K., \& Skinner, D. J. (2010). Implications for GAAP from an analysis of positive research in accounting. Journal of Accounting and Economics, 50(2-3), 246-286.

Lang, M., Raedy, J. S., \& Wilson, W. (2006). Earnings management and cross listing: Are reconciled earnings comparable to US earnings?. Journal of Accounting and Economics, 42(1-2), 255-283.

Leuz, C., Nanda, D., \& Wysocki, P. D. (2003). Earnings management and investor protection: an international comparison. Journal of Financial Economics, 69(3), 505-527.

Leuz, C., \& Wysocki, P. D. (2016). The Economics of Disclosure and Financial Reporting Regulation: Evidence and Suggestions for Future Research. Journal of Accounting Research, 54(2), 525-622.

Lev, B. (1988). Toward a theory of equitable and efficient accounting policy. The Accounting Review, 1-22.

Levitt, A. (1998). Speech by SEC Chairman: A Financial Partnership. Disponível em: < https://www.sec.gov/news/speech/speecharchive/1998/spch227.htm>

Liu, C., Yip Yuen, C., Yao, L., \& Chan, S. (2014). Differences in earnings management between firms using US GAAP and IAS/IFRS. Review of Accounting \& Finance, 13(2), 134.

Lobo, G. J., \& Zhou, J. (2006). Did conservatism in financial reporting increase after the Sarbanes-Oxley Act? Initial evidence. Accounting Horizons, 20(1), 57-73.

Lopes. A. B.(2002). A informação contábil e o mercado de capitais. São Paulo: Pioneira Tompson Learning.

Lourenço, I. M. E. C., \& Branco, M. E. M. D. A. D. C. (2015). Main consequences of IFRS adoption: Analysis of existing literature and suggestions for further research. Revista Contabilidade \& Finanças, 26(68), 126-139.

Martinez, A. L.(2001). " Gerenciamento" dos resultados contábeis: estudo empírico das companhias abertas brasileiras. 2001. Tese (Doutorado em Controladoria e Contabilidade: Contabilidade) - Faculdade de Economia, Administração e Contabilidade, Universidade de São Paulo, São Paulo.

Matsumoto, A. S., \& Parreira, E. M. (2009). Uma pesquisa sobre o gerenciamento de resultados contábeis: causas e consequências. Revista Contabilidade, Gestão e Governança, 10(1), 141-157.

Mitra, S., Jaggi, B., \& Hossain, M. (2013). Internal control weaknesses and accounting conservatism: Evidence from the post-Sarbanes-Oxley period. Journal of Accounting, Auditing \& Finance, 28(2), 152-191.

Moraes, E. A., Goncalves, R.S., \& Niyama, J. K. (2015). Ambiente regulatório e evidenciação social: uma análise das divulgações de empresas brasileiras listadas na BM\&FBOVESPA. Advances in Scientific and Applied Accounting, 8(2), 218-243.

Morais, A. I., \& Curto, J. D. (2008). Accounting quality and the adoption of IASB standards: portuguese evidence. Revista Contabilidade \& Finanças, 19(48), 103-111.

Mussalo, Veera.(2015) The effect of earnings management on audit fees: evidence from the manufacturing industry. Dissertação (Mestrado). Aalto University School of Business. 2015. Disponível em: < http://epub.lib.aalto.fi/fi/ethesis/pdf/14176/hse_ethesis_14176.pdf>. Acesso: 31 ago 2016.

Niyama, J. K., da Costa, F. M., Dantas, J. A., \& Borges, E. F. (2011). Evolução da regulação da auditoria independente no Brasil: análise crítica, a partir da teoria da regulação. Advances in Scientific and Applied Accounting, 4(2), 127-161.

Niyama, J. K., Rodrigues, A. M. G., \& Rodrigues, J. M. (2015). Algumas reflexões sobre contabilidade criativa e as normas internacionais de contabilidade. Revista Universo Contábil, 11(1), 69-87.

Paulo, E.(2007). Manipulação das informações contábeis: uma análise teórica e empírica sobre os modelos operacionais de detecção de gerenciamento de resultados. São Paulo. 2007. Tese (Doutorado em 
Contabilidade) -. Faculdade de Economia. Administração e Contabilidade da Universidade de São Paulo.

Paulo, E., \& Martins, E. (2007). Análise da qualidade das informações contábeis nas companhias abertas. Anais do Encontro da Associação Nacional de Pós-Graduação e Pesquisa em Administração, São Paulo, SP, Brasil, 31, 1-16.

Pohlmann, M.\& Alves, F. (2004). Regulamentação. In: Lopes, A.; Iudícibus, S (Coord.). Teoria avançada da contabilidade. São Paulo: Editora atlas.

Posner, R. A. Theories of economic regulation. 1974. Disponível em:< https://core.ac.uk/download/pdf/6690483.pdf>. Acesso em: 10 jul 2016.

Qiang, X. (2007). The effects of contracting, litigation, regulation, and tax costs on conditional and unconditional conservatism: Cross-sectional evidence at the firm level. The Accounting Review, 82(3), 759-796.

Rodrigues, J. M.(2012). Convergência contábil internacional: uma análise da qualidade da informação contábil em razão da adoção dos padrões internacionais de contabilidade editados pelo IASB. 2012. Tese. (Doutorado em Contabilidade), UnB,UFPB,UFRN, Brasília.

Schipper, K. (1989). Earnings management. Accounting Horizons, 3(4), 91.

Schipper, K., \& Vincent, L. (2003). Earnings quality. Accounting Horizons, 17, 97-110.

Soderstrom, N. S., \& Sun, K. J. (2007). IFRS Adoption and Accounting Quality: A Review. European Accounting Review, 16(4), 675-702.

Sorrentino, M., Cossu, F., \& Smarra, M. (2015). The "production” of accounting information between regulatory and free market approach: an (eternally) open issue. Journal of Modern Accounting and Auditing, 11(1), 1-9.

Stigler, G. J. (1971). The theory of economic regulation. The Bell Journal of Economics and Management Science, 3-21.

Tavares, M. F. N.; Anjos, L. C. M.(2014). Teoria da regulação x teoria da contabilidade. In: Niyama, J K. (Coord.). Teoria avançada da contabilidade. São Paulo: Atlas, 38 - 66.

Tucker, J. W., \& Zarowin, P. A. (2006). Does income smoothing improve earnings informativeness?. The Accounting Review, 81(1), 251-270.

Ugrin, J. C., Mason, T. W., \& Emley, A. (2017). Culture's consequence: The relationship between incomeincreasing earnings management and IAS/IFRS adoption across cultures. Advances in Accounting, 37, $140-151$.

Viscusi, W. K., Vernon, J. M, \& Harrington, J. E. (2005). Economics of regulation and antitrust. MIT press.

Watts, R. L. (2003). Conservatism in accounting part I: Explanations and implications. Accounting Horizons, 17(3), 207-221.

Watts, R. L., \& Zimmerman, J. L. (1978). Towards a positive theory of the determination of accounting standards. The Accounting Review, 53(1), 112-134.

Willekens, W. \& Dutillieux, M.(2009). The impact of SOX on earnings quality outside the US: Evidence from Belgian subsidiaries of US listed companies. In: ICRAA Conference at the University of Florida. Disponível: < https://lirias.kuleuven.be/handle/123456789/213453>. Acesso: 14 julho 2016.

Wolk, H. I., Dodd, J. L., \& Tearney, M.G. (2004). Accounting theory: conceptual issues in a political and economic environment. Sixth Edition.

Zeghal, D., Chtourou, S. M., \& Fourati, Y. M. (2012). The effect of mandatory adoption of IFRS on earnings quality: Evidence from the European Union. Journal of International Accounting Research, 11(2), 125.

Zeghal, D., Chtourou, S., \& Sellami, Y. (2011). An analysis of the effect of mandatory adoption of IAS/IFRS on earnings management. Journal of International Accounting, Auditing and Taxation, 20(2), 61-72.

Zeghal, D., \& Lahmar, Z. (2016). The impact of IFRS adoption on accounting conservatism in the European Union. International Journal of Accounting and Financial Reporting, 6(1), 127-160.

Zhang, J.(2011). The effect of IFRS adoption on accounting conservatism-New Zealand perspective. 2011. Tese de Doutorado. Auckland University of Technology.

Zhou, J. (2008). Financial reporting after the Sarbanes-Oxley Act: Conservative or less earnings management?. Research in Accounting Regulation, 20, 187-192. 